\title{
DISPARATE EFFECTS OF INFUSED NUTRIENTS ON DELAYED GLUCOPRIVIC FEEDING AND HYPOTHALAMIC NOREPINEPHRINE TURNOVER ${ }^{1}$
}

\author{
STEVEN I. BELLIN ${ }^{2}$ AND SUE RITTER ${ }^{3}$
}

Department of Veterinary and Comparative Anatomy, Pharmacology and Physiology, College of Veterinary Medicine, Washington State University, Pullman, Washington 99164

\begin{abstract}
We investigated the effects of isocaloric nutrient infusions on delayed glucoprivic feeding (DGF) and on glucoprivation-induced increases in hypothalamic norepincphrine (NE) turnover in order to identify non-orogastric conditions involved in the termination of these glucoprivic responses. Rats were infused with various nutrients for $30 \mathrm{~min}, 1.5$ to $2 \mathrm{hr}$ after insulin ( $2.5 \mathrm{units} / \mathrm{kg}$, s.c.) or saline injection. Feeding was measured in a 2-hr test 4 to $6 \mathrm{hr}$ later. Nutrients (D-glucose, D-fructose, and DL- $\beta$-hydroxybutyrate) were selected for infusion on the basis of their differing abilities to serve as substrates for brain energy metabolism. The caloric value of the infusate $(7.9 \mathrm{kcal})$ was equated with the number of calories which effectively abolish DGF when ingested as pelleted rat chow. We found that hypothalamic NE turnover (decline of NE concentration after $\alpha$-methyl-p-tyrosine) was normalized by infusion of $\beta$-hydroxybutyrate or glucose but not fructose. Thus, the entry of nutrients into the brain may be both necessary and sufficient to reverse the effects of glucoprivation on NE neurons. Delayed feeding, however, was totally abolished only by $\beta$-hydroxybutyrate, a substance which can be utilized by both brain and most peripheral tissues. Fructose attenuated feeding and glucose had no effect. The failure of fructose to abolish DGF totally may reflect its exclusion from brain. However, its partial effectiveness may indicate that a signal of peripheral origin contributes to the termination of DGF. The ineffectiveness of infused glucose is puzzling but, interpreted in the light of other data, may indicate that preabsorptive signals are required for termination of DGF by glucose. Finally, it has been suggested that NE neurons may mediate glucoprivic feeding. However, since glucose infusions normalize postglucoprivic NE turnover without suppressing delayed glucoprivic feeding, the persistence of enhanced NE turnover rates cannot account for the persistence of feeding after glucoprivation.
\end{abstract}

The glucoprivic control of food intake (Epstein et al., 1975) can be exercised experimentally by insulin-induced glucoprivation or by peripheral intracerebroventricular injection of antiglycolytic glucose analogues (Smith and Epstein, 1969; Booth, 1972; Muller et al., 1974; Miselis and Epstein, 1975; Ritter and Slusser, 1980; Slusser and Ritter, 1980). Therefore, it has been assumed that, under this control, increased feeding requires ongoing glucoprivation. Recently, however, it has been shown that glucoprivically initiated feeding persists after other signs of glucoprivation have abated (i.e., 6 to $8 \mathrm{hr}$ after injection of either insulin or 2-deoxy-D-glucose (R. C. Ritter et al.,

${ }^{1}$ This work was supported by Public Health Service Grant AM 28087 to S. R. and a Sigma Xi grant-in-aid of research to S. I. B. We wish to thank Ms. Kathryn Bayne for her excellent technical assistance.

${ }^{2}$ This paper was submitted in partial fulfillment of the requirements for a doctoral degree. S. I. B. is currently a postdoctoral fellow at the University of Iowa, Department of Psychology.

${ }^{3}$ To whom correspondence should be addressed.
1978)). Consequently, some neural or metabolic sequel of glucoprivation, persisting longer than the glucoprivic episode itself, may be responsible for the increased feeding in response to prior glucoprivation. One candidate for such a sequel is increased activity of hypothalamic noradrenergic (NE) neurons. Infusion of exogenous NE into the hypothalamus increases feeding (Grossman, 1960; Booth, 1968; Slangen and Miller, 1969; Leibowitz, 1975; Ritter and Epstein, 1975; Ritter et al., 1975). Furthermore, there is evidence that intact hypothalamic catecholamine neurons are necessary for the initiation of glucoprivic feeding (Wayner et al., 1971; Marshall and Teitelbaum, 1973; Stricker et al., 1975; S. Ritter et al., 1978).

In an earlier series of experiments, we showed that hypothalamic NE turnover was increased by glucoprivation (Bellin and Ritter, 1981; Ritter et al., 1981). Ingestion of pelleted rodent laboratory chow normalized these clevated rates of $\mathrm{NE}$ turnover to values indistinguishable from those observed in saline-injected rats. Furthermore, 
we found that, in the absence of food, NE turnover remained elevated even after spontaneous glucorestoration had occurred. Thus, increased hypothalamic NE turnover might be a part of the mechanism by which feeding is maintained in the apparent absence of glucoprivation. This hypothesis was strengthened by subsequent work in which we demonstrated that ingestion of either rat chow or glucose not only abolished delayed glucoprivic feeding but also abolished enhanced rates of hypothalamic NE turnover (Ritter et al., 1981).

Because our previous experiments did not discriminate between pre- and postabsorptive consequences of ingestion, we have performed additional experiments utilizing intravenous nutrient infusions in order to determine the importance of postabsorptive signals in abolishing glucoprivation-induced increases in feeding and hypothalamic NE turnover. In parallel experiments, reported separately, we have considered the contribution of preabsorptive parameters of food ingestion in terminating glucoprivic responses (Ritter et al., 1981).

In the experiments that follow, we have made further use of the delayed access design (R. C. Ritter et al., 1978). This experimental protocol permits evaluation of feeding and NE turnover at a time when the stress of acute glucoprivation has apparently subsided. Temporal removal from the glucoprivic episode itself is particularly important with respect to measures of NE turnover since stresses of many kinds enhance brain NE neuron activity (Maynert and Levi, 1964; Thierry et al., 1968; Stone, 1973; Ritter and Ritter, 1977). Additionally, the delayed access design permits intravenous nutrient infusions to be made after the glucoprivic stimulus is fully developed but at least $3.5 \mathrm{hr}$ prior to the measurement of feeding and NE turnover. These facets of the design have two important consequences. First, nonspecific effects of nutrient infusion are less likely to alter either feeding or NE turnover. Second, since the glucoprivic episode is allowed to develop fully prior to the commencement of nutrient infusion, any effects of these infusions must relate specifically to the termination of glucoprivation-induced responses rather than simply to the prevention of the glucoprivic stimulus itself.

In the experiments reported in this paper, we made intravenous infusions of glucose, fructose, and the ketone body, $\beta$-hydroxybutyrate ( $\mathrm{BOH})$, in order to determine whether postabsorptive signals capable of normalizing hypothalamic NE turnover rates after a glucoprivic episode are also capable of abolishing glucoprivically induced feeding. Our results suggest that the persistence of enhanced turnover rates cannot account for the persistence of feeding after glucoprivation.

\section{Materials and Methods}

Adult male Sprague-Dawley rats weighing 400 to 500 gm were housed individually in suspended wire mesh cages in a temperature-controlled room $\left(22 \pm 1^{\circ} \mathrm{C}\right)$ illuminated for $12 \mathrm{hr}$ during the day ( 7 A.M. to 7 P.M.). All studies were conducted in the animals' home cages during the light phase. Pelleted chow and tap water were freely available to all rats except when noted.

The experimental design used in all studies was as follows: (1) free access to fresh pelleted chow was per- mitted from 8 to 9 A.M.; (2) food was removed and insulin (Iletin, Lilly, 2.5 units/kg) or saline was injected subcutaneously at 9 A.M.; (3) food was withheld for $6 \mathrm{hr}$ except during a 30 -min period from 1.5 to $2 \mathrm{hr}$ postinsulin injection, during which time, rats were infused intra-atrially with a concentrated nutrient solution (see below) or saline; (4) food intake or catecholamine turnover was measured during the postglucoprivic period, from 6 to $8 \mathrm{hr}$ after insulin or saline injections. When blood glucose determinations were required, $30 \mu \mathrm{l}$ of tail vein blood was collected in microcapillary tubes at 8:50 A.M. and at $1.5,3,4,5$, and $6 \mathrm{hr}$ after insulin or saline injection and subsequently assayed using the glucose oxidase method (Saifer and Gerstenfeld, 1958). When catecholamine turnover was measured, food was not returned during the postglucoprivic period. Instead, rats were injected subcutaneously with $350 \mathrm{mg} / \mathrm{kg}$ of $\alpha$ methyl-p-tyrosine (AMT, $100 \mathrm{mg} / \mathrm{ml}$ of distilled water) $5.5 \mathrm{hr}$ after insulin or saline injection, and animals from each treatment group were sacrificed $0.5,1$, and $2 \mathrm{hr}$ later (Costa, 1970; Weiner, 1974; Cooper et al., 1978; Bellin and Ritter, 1981). Hypothalamus and telencephalon were dissected, as described by Lorden et al. (1975), and analyzed fluorometrically for catecholamine content using a modification of the technique described by Jacobowitz et al. (1967).

We have shown that ingestion of at least $2.5 \mathrm{gm}$ of pelleted chow is required to abolish postglucoprivic feeding behaviors and elevated rates of hypothalamic NE utilization (Ritter et al., 1981). Therefore, in experiments (described below) designed to investigate postabsorptive parameters of food intake capable of affecting these insulin-associated events, infusates calorically equivalent to $2.5 \mathrm{gm}$ of pelleted chow $(7.9 \mathrm{kcal})$ were administered.

Fifty catheterized rats were divided randomly into five treatment groups. Seventeen animals received saline injections at 9 A.M. The remaining subjects were administered insulin at this time. One and one-half hours later, saline-injected rats were infused with sterile physiological saline $(4.4 \mathrm{ml})$ and insulin-treated rats received infusions of either saline $(n=12 ; 4.4 \mathrm{ml})$ or $2.4 \mathrm{M} \mathrm{D}$-glucose $(n=9$; $4.4 \mathrm{ml}$ ), D-fructose $(n=6 ; 4.4 \mathrm{ml})$, or $\mathrm{DL}-\beta$-hydroxybutyrate $(n=6 ; 5.1 \mathrm{ml})$ solutions. In this study, blood samples were collected and analyzed as described. A similar study was repeated 2 days later in the absence of food, but blood samples were not taken at this time. Instead, pelleted chow was returned to each animal at 3 P.M. and food intake was monitored to the nearest $0.1 \mathrm{gm}$ during the subsequent 2 -hr period.

In a separate group of 60 naive rats equally divided into five treatment blocks, these experiments were repeated in order to determine the effects of these infusates on catecholamine turnover during the postglucoprivic period.

Catecholamine concentrations in insulin-treated rats did not differ significantly from values recorded in untreated controls at the time of AMT injections in any turnover experiment. Therefore, catecholamine concentrations were calculated and expressed as a percentage of the untreated control values.

Nonpaired bidirectional $t$ tests were used to analyze blood glucose, postglucoprivic feeding, and catechola- 
mine content data. Statistical results from individual parameters were confirmed by a one-way analysis of variance.

\section{Results}

The magnitude of delayed glucoprivic feeding observed in nutrient-infused rats receiving insulin or saline injections is shown in Figure 1. In insulin-injected, salineinfused subjects, approximately $6.0 \mathrm{gm}$ of pelleted rodent food was ingested during the delayed feeding period. Glucose infusions administered during insulin-induced glucoprivic episodes did not alter the magnitude of delayed feeding. Fructose infusions significantly attenuated the amount of food consumed during the delayed feeding trial $(\ddagger=p<0.01)$. However, this level of intake remained statistically greater than that amount eaten by salineinjected rats receiving saline infusions $(*=p<0.001)$. Finally, the intravenous delivery of $\mathrm{BOH}$ abolished the enhanced feeding that was otherwise observed during the delayed test in glucodeprived, saline-infused rats.

In Figure 2, the blood glucose concentrations recorded from these same animals prior to and following nutrient infusions are presented. Blood glucose levels in all insulin-treated subjects fell to approximately $20 \mathrm{mg} \%$ by 1.5 $\mathrm{hr}$ postinjection and returned spontaneously to preinjec-

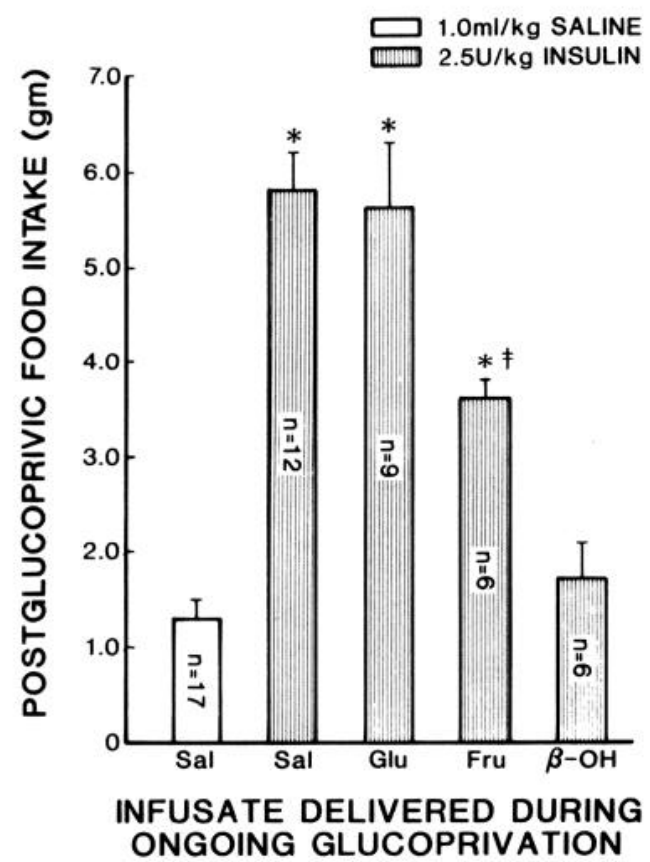

Figure 1. Effect of infused nutrients on food intake in a delayed feeding test conducted during the postglucoprivic period 6 to $8 \mathrm{hr}$ after insulin $(2.5$ units $/ \mathrm{kg}$, s.c.) or saline $(1.0 \mathrm{ml} /$ $\mathrm{kg}$ ) injection. Nutrients or saline were delivered via intra-atrial catheters from 1.5 to $2 \mathrm{hr}$ postinjection. Nutrient infusions were calorically equivalent to $2.5 \mathrm{gm}$ of pelleted food $(7.9 \mathrm{kcal})$, an amount of food which abolishes delayed glucoprivic feeding. Glucose infusion failed to alter delayed glucoprivic feeding ( $p$ $\geq 0.50$ versus insulin-Sal). Fructose significantly attenuated ( $\ddagger$ $=p \leq 0.01$, insulin-Fru versus insulin-Sal) but did not abolish postglucoprivic feeding $(*=p \leq 0.01$, insulin-Fru versus salineSal). $\beta$-Hydroxybutyrate abolished delayed glucoprivic feeding ( $p \geq 0.50$ versus saline-Sal). The values presented are the means \pm SEM. The abbreviations used are: Fru, fructose; Glu, glucose; $\beta$-OH, $\beta$-hydroxybutyrate; Sal, saline.

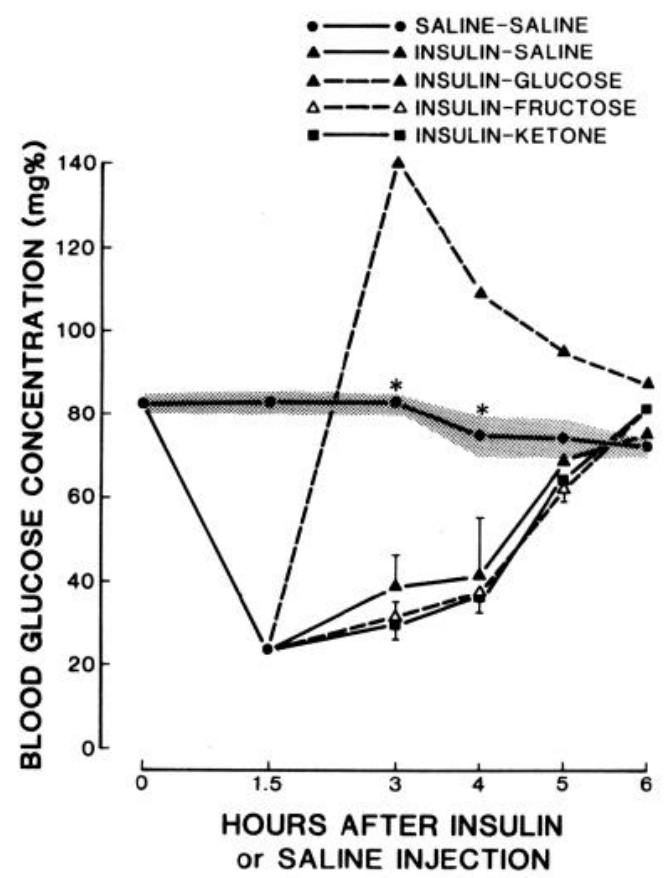

Figure 2. Blood glucose concentrations from rats receiving intra-atrial infusions of calorically equivalent nutrients 1.5 to 2 $\mathrm{hr}$ after insulin injection (2.5 units/kg, s.c.). The stippled area represents the $95 \%$ confidence interval for blood glucose values sampled from saline-injected rats $(1.0 \mathrm{ml} / \mathrm{kg})$. The values shown are the means $\pm \mathrm{SD}(*=p \leq 0.01$ versus all treatments).

tion values in saline-, fructose- and $\mathrm{BOH}$-infused animals by 5 to $6 \mathrm{hr}$ after insulin administration. Following glucose infusion, however, glucorestoration was accelerated so that blood glucose concentrations met or exceeded preinjection values by 3 to $4 \mathrm{hr}$ after insulin injection.

Figure 3 shows the effects of nutrient infusions on the postglucoprivic hypothalamic NE concentration following inhibition of catecholamine biosynthesis with AMT. Without exception, the levels of NE detected $2 \mathrm{hr}$ after AMT in insulin-treated, saline-infused rats were significantly less than the levels recorded from any salineinjected, nutrient-infused subject $(*=p<0.01 ; * *=p$ $<0.001$ ). In addition, hypothalamic NE concentrations in glucodeprived rats receiving either glucose or $\mathrm{BOH}$ infusions were equal to or more than the 2 -hr post-AMT concentrations seen in their saline-injected counterparts. However, at this time, neurotransmitter levels in insulintreated, fructose-infused animals remained depressed when compared to values recorded in their saline-injected counterparts.

In telencephalic tissue (Table I), no effect of prior glucoprivation on either the NE or dopamine turnover rate was apparent during the postglucoprivic period. In glucodeprived rats, infusion of fructose or $\mathrm{BOH}$, however, decelerated NE turnover to rates lower than those observed in controls. Fructose infusion, but not $\mathrm{BOH}$, also slowed the apparent rate of dopamine utilization in insulin-injected subjects.

\section{Discussion}

Infusion of either $\mathrm{BOH}$ or glucose during ongoing glucoprivation abolished the elevated hypothalamic NE 


\section{HYPOTHALAMUS}

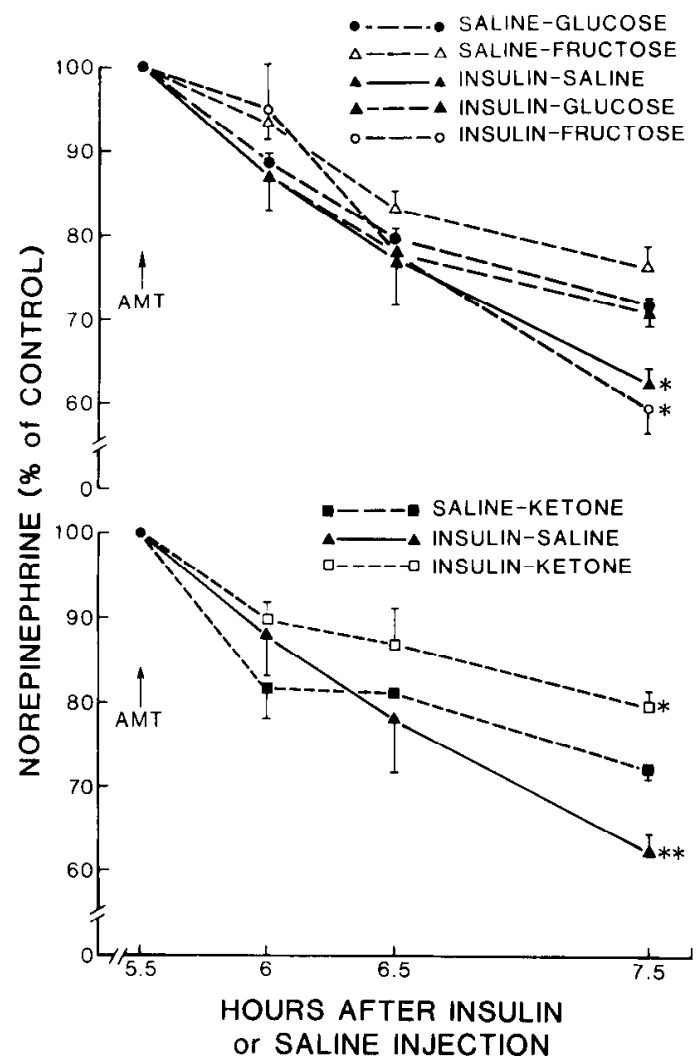

Figure 3. Effect of infused nutrients on hypothalamic norepinephrine turnover during the postglucoprivic period 5.5 to $7.5 \mathrm{hr}$ after insulin injection (2.5 units $/ \mathrm{kg}$, s.c.). Turnover is estimated by the rates of decline of transmitter concentration after $\alpha$-methyl-p-tyrosine ( $350 \mathrm{mg} / \mathrm{kg}$, s.c.). Food was removed from the animals at the time of the insulin injection. Fquicaloric nutrient solutions $(7.9 \mathrm{kcal})$ or saline were delivered via intraatrial catheters over a $30-\mathrm{min}$ period from 1.5 to $2 \mathrm{hr}$ after insulin injection. Turnover rate was potentiated by insulin. Infusions of either glucose or the ketone body, $\beta$-hydroxybutyrate, normalized NE turnover rates $(*=p \leq 0.01$, insulin-glucose versus insulin-saline; $* *=p \leq 0.001$, insulin-ketone versus insulin-saline, respectively). Fructose infusion, however, had no effect on NE turnover ( $p \geq 0.10$, insulin-fructose versus insulinsaline). Concentrations are expressed as means $\pm \mathrm{SD}$.

turnover rate otherwise observed during the postglucoprivic period. Infusion of fructose had no effect. In contrast, $\mathrm{BOH}$ was the only infusate which abolished postglucoprivic feeding. Fructose produced only an attenuation, and infusion of glucose failed to produce any reduction in postglucoprivic feeding.

These results show that infusions of $\mathrm{BOH}$ or glucose, nutrients which pass the blood-brain barrier and are metabolized by the brain (Maker et al., 1976; Robinson and Williamson, 1980), are capable of normalizing hypothalamic NE turnover after glucoprivation. In contrast, fructose does not pass the blood-brain barrier (Park et al., 1957; Oldendorf, 1971). The failure of fructose infusion to diminish the glucoprivation-induced elevation of $\mathrm{NE}$ turnover therefore suggests that normalization of $\mathrm{NE}$ turnover requires entry of utilizable nutrients into the brain (Stricker et al., 1977; Rowland and Stricker, 1979).
The lack of correspondence of telencephalic NE and dopamine turnover with prior glucoprivation, delayed feeding, or nutrient infusion is generally consistent with our previous results (Bellin and Ritter, 1981) and suggests that these catecholamine systems may not be directly involved in delayed glucoprivic feeding. Although some studies provide evidence for an involvement of various brain dopamine systems in feeding behavior (e.g., Ungerstedt, 1971; Stricker and Zigmond, 1974; McCaleb and Myers, 1979; Heffner et al., 1980) and reveal alterations of dopamine metabolism with changes in nutrient availability to the brain (McCaleb and Myers, 1979; Saller and Chiodo, 1980), other studies have failed to find such evidence (Ritter et al., 1975; Van der Gugten et al., 1977; Van der Gugten and Slangen, 1977). Elucidation of the role of dopamine systems in these phenomena requires further study.

The effects of intravenous nutrient infusions on glucoprivation-induced feeding appear to be more complex than the effects that we observed on NE turnover. Infusion of the ketone body, $\mathrm{BOH}$, abolished delayed access glucoprivic feeding. $\beta$-Hydroxybutyrate is an endogenous alternate fuel for most tissues. Of importance is the fact that this substance can be taken up and utilized by most brain areas as a substrate for energy metabolism in direct proportion to its concentration in the blood (Robinson and Williamson, 1980). Thus, BOH may abolish feeding by reversing a glucoprivation-induced metabolic signal which triggers or maintains this response. If $\mathrm{BOH}$ influences glucoprivic feeding by this mechanism, then it is possible that this response is controlled by receptors

TABLE I

Effect of infused nutrients on telencephalic norepinephrine and dopamine turnover observed during the postglucuprivic period 5.5 to $7.5 \mathrm{hr}$ following subcutaneous insulin injection (2.5 units $/ \mathrm{kg})^{a}$

\begin{tabular}{lcc}
\hline \multicolumn{1}{c}{ Treatment $^{b}$} & $\mathrm{NE}^{c}$ & $\mathrm{DA}^{\mathrm{c}, d}$ \\
\hline & & $\%^{\circ}$ \\
Saline-glucose & $69.8 \pm 0.4$ & $62.8 \pm 0.6$ \\
Insulin-saline & $68.2 \pm 3.4$ & $60.7 \pm 3.1$ \\
Insulin-glucose & $65.9 \pm 2.0$ & $61.3 \pm 1.6$ \\
& & \\
Saline-fructose & $70.1 \pm 1.8$ & $64.3 \pm 5.8$ \\
Insulin-saline & $68.2 \pm 3.4$ & $60.7 \pm 3.1$ \\
Insulin-fructose & $74.5 \pm 3.0^{e}$ & $68.6 \pm \mathbf{4 . 6}$ \\
& & \\
Saline-ketone & $71.1 \pm 0.6$ & $66.0 \pm 5.2$ \\
Insulin-saline & $68.2 \pm 3.4$ & $60.7 \pm 3.1$ \\
Insulin-ketone & $76.4 \pm 3.4^{e}$ & $66.7 \pm \mathbf{4 . 0}$ \\
\hline
\end{tabular}

a Turnover is estimated by the rates of decline of transmitter concentrations after $\alpha$-methyl- $p$-tyrosine ( $350 \mathrm{mg} / \mathrm{kg}$, s.c.).

${ }^{b}$ Food was removed from the animals at the time of insulin or saline injection. One and one-half hours after insulin or saline injection, a nutrient solution equaling $7.9 \mathrm{kcal}$ or saline was delivered via an intraatrial catheter over a $30-$ min period. AMT was administered to each subject at $5.5 \mathrm{hr}$ post-insulin injection. Infusates included $4.4 \mathrm{ml}$ of either physiologically sterile saline, D-glucose, or D-fructose or $5.1 \mathrm{ml}$ of the ketone body DL- $\beta$-hydroxybutyrate.

${ }^{c}$ Values are those recorded $2 \mathrm{hr}$ after AMT and are expressed as a percentage $\pm \mathrm{SD}$ of zero time catecholamine concentrations in untreated controls.

${ }^{d} \mathrm{DA}$, dopamine.

${ }^{e} p \leq 0.05$, insulin-fructose or insulin-ketone versus insulin-saline. 
which are sensitive to the availability of oxidizable substrate in general rather than to the availability of glucose specifically (Flatt et al., 1974; Stricker et al., 1977). The liver has been suggested as a possible site for a subpopulation of receptors controlling glucoprivation-induced feeding (Russek, 1970, 1975; Novin et al., 1973; Friedman and Stricker, 1976). However, since hepatic tissue cannot utilize ketone bodies (Krebs et al., 1971), it seems improbable that this tissue could play such a role.

Alternatively, $\mathrm{BOH}$ may abolish glucoprivic responses not by substituting for glucose as an energy source but by activating a satiety signal which is independent of and unrelated to the glucoprivic control. Such a satiety mechanism may compete with glucoprivically induced hunger and overwhelm the feeding response. Similarly, the high concentrations of $\mathrm{BOH}$ used in our study far exceed physiological levels and may have inhibited feeding by making the animals sick. Possibly, the 4-hr delay between the end of the infusion and the beginning of the feeding test was inadequate to allow for the dissipation of any adverse consequences of ketone body infusion. In this regard, however, it should be noted that NE turnover was normalized during the time of the delayed feeding test after $\mathrm{BOH}$ infusion, an effect that would not be expected if the stressful aspects of the infusion were still prominent at that time.

Although fructose infusions failed to abolish glucoprivic feeding in the delayed access experiment, this substance did produce a significant attenuation of food intake. These findings are consistent with those of other investigators who have demonstrated attenuation of insulin-elicited feeding following intravenous fructose infusions (Stricker et al., 1977; Rowland and Stricker, 1979; Granneman and Friedman, 1980). Moreover, the differential effectiveness of $\mathrm{BOH}$ and fructose in abolishing glucoprivic feeding suggests that abolition of feeding requires the cooperative action of signals arising from receptors on both sides of the blood-brain barrier. If so, the greater effectiveness of $\mathrm{BOH}$ would reflect its access to receptors in both locations. Fructose may be less effective due to its inaccessibility to receptors within the brain.

Perhaps our most perplexing result is the failure of infused glucose to terminate feeding in the delayed access design. This finding, also reported by others (Smith, 1966; Booth and Pitt, 1968; Yin and Tsai, 1973; Ritter and Miller, 1978), appears to contradict the results of Stricker et al. (1977) showing that co-infusion of glucose and insulin prevented glucoprivic feeding. However, their experiments were conducted in such a way that the infused nutrients were likely to have prevented the development of glucoprivation-induced caloric deprivation. Consequently, we believe that their results are more relevant to the conditions which surround the initiation of glucoprivic feeding rather than those which are required for its termination.

It is interesting that, unlike infused glucose, ingestion of an equicaloric glucose solution totally abolished feeding in a delayed access paradigm (Ritter et al., 1981). Taken together, these results suggest that preabsorptive stimuli play an essential role in the suppression of feeding by glucose. Because we have shown in experiments re- ported elsewhere that saccharin ingestion has no effect on delayed glucoprivic feeding (Ritter et al., 1981), we can rule out the notion that sweet taste alone is sufficient to abolish the response. In fact, saccharin ingestion significantly enhanced glucoprivic feeding. However, when glucose is infused intravenously during saccharin ingestion, delayed glucoprivic feeding is abolished (S. Ritter and N. L. Pelzer, personal communication). Therefore, it seems that appropriate preabsorptive signals must exist with glucorestoration to terminate feeding. In contrast to glucose, fructose is no more effective when it is ingested than when it is infused (Rowland and Stricker, 1979; Ritter et al., 1981). Thus, unlike glucose, the failure of fructose to abolish delayed glucoprivic feeding cannot be attributed to the absence of preabsorptive stimuli.

Although we have no data at this time which would specify the nature of the preabsorptive signal(s) necessary for the termination of delayed feeding by glucose, one candidate for such a signal would be orogastrically mediated insulin release. The presence of insulin is required by most tissues for the efficient utilization of glucose (Mayer, 1955; Larner and Haynes, 1975). However, due to the short half-life of insulin in plasma (Larner and Haynes, 1975; Anika et al., 1980), the insulin injected at the onset of our experiment may have dissipated by the time our nutrient infusions were begun. Moreover, after glucoprivation, the release of insulin is inhibited (Smith and Root, 1969; Frier et al., 1980) and intravenous glucose infusions do not cause plasma insulin levels to rise (Somogyi, 1951). In contrast, if animals are permitted to eat after a glucoprivic episode, plasma insulin levels rise sharply (Smith and Root, 1969; Frier et al., 1980). The release of insulin under these conditions by food ingestion is probably mediated by vagal afferents or gastrointestinal hormones (Fischer et al., 1972; Hommel et al., 1972; Strubbe and Steffens, 1975; Steffens, 1976; Anika et al., 1980; Granneman and Friedman, 1980). We propose that the effectiveness of ingested or infused substances in terminating glucoprivic feeding in our experiment depends, in part, on their ability to be taken up and metabolized by tissues outside of the blood-brain barrier. Thus, ingested glucose would be more effective in this regard than infused glucose, since it would be more likely to co-exist in the circulation with the insulin required for its uptake. The effectiveness of $\mathrm{BOH}$ or fructose in suppressing delayed glucoprivic feeding would be consistent with this interpretation. Unlike glucose, the uptake of fructose and $\mathrm{BOH}$ is not enhanced by insulin (Park et al., 1957; Williamson et al., 1975; Robinson and Williamson, 1980). Therefore, the contribution of these substances to the suppression of delayed glucoprivic feeding should not be diminished either by the absence of insulin or by a possible postglucoprivic insensitivity of tissues to insulin (Frier et al., 1980).

Finally, we found that delayed glucoprivic feeding persisted after glucose infusions even though the glucoprivation-induced increase in hypothalamic NE turnover was abolished by glucose. Conversely, food intake was significantly reduced by fructose, while glucoprivationinduced elevations in postglucoprivic hypothalamic NE turnover rates were not altered by this substance. The dissociation of enhanced hypothalamic NE turnover 
rates and feeding behavior may indicate that hypothalamic NE neurons do not mediate glucoprivic feeding.

\section{References}

Anika, S. M., T. R. Houpt, and K. A. Houpt (1980) Insulin as a satiety hormone. Physiol. Behav. 25: 21-23.

Bellin, S. I., and S. Ritter (1981) Insulin-induced elevation of hypothalamic norepinephrine turnover persists after glucorestoration unless feeding occurs. Brain Res. 217: 327-337.

Booth, D. A. (1968) Mechanism of action of norepinephrine in eliciting an eating response on injection into the rat hypothalamus. J. Pharmacol. Exp. Ther. 160: 336-348.

Booth, D. A. (1972) Modulation of the feeding response to peripheral insulin, 2-deoxyglucose or 3-O-methylglucose injection. Physiol. Behav. 8: 1069-1076.

Booth, D. A., and M. E. Pitt (1968) The role of glucose in insulin-induced feeding and drinking. Physiol. Behav. 3: 447453.

Cooper, J. R., F. E. Bloom, and R. H. Roth (1978) The Biochemical Basis of Neuropharmacology, pp. 134-139, Oxford University Press, New York.

Costa, E. (1970) Simple neuronal models to estimate turnover rate of noradrenergic transmitters in vivo. Adv. Biochem. Psychopharmacol. 2: 169-204.

Epstein, A. N., S. Nicolaides, and R. Miselis (1975) The glucoprivic control of food intake and the glucostatic theory of feeding behavior. In Neural Integration of Physiological Mechanisms and Behavior, G. J. Mogenson and F. R. Calarescu, eds., pp. 148-168, University of Toronto Press, Toronto.

Fischer, U., H. Hommel, M. Ziegler, and R. Michael (1972) The mechanism of insulin secretion after oral glucose administration. I. Multiphasic course of insulin mobilization after oral administration of glucose in conscious dogs. Differences to the behavior after intravenous administration. Diabetologia 8: 104-119.

Flatt, J. P., L. Blackburn, G. Randers, and J. B. Stanbury (1974) Effects of ketone body infusion on hypoglycemic reaction in postabsorptive dogs. Metabolism 23: 151-158.

Friedman, M. I., and E. M. Stricker (1976) The physiological psychology of hunger: A physiological perspective. Psychol. Rev. 83: 409-431.

Frier, B. M., R. J. M. Corrall, J. P. Ashby, and J. D. Baird (1980) Attenuation of the pancreatic beta cell response to a meal following hypoglycaemia in man. Diabetologia 18: 297300 .

Granneman, J., and M. I. Friedman (1980) Interaction of hepatic and cerebral receptors in the control of feeding stimulated after the recovery from acute glucoprivation in rats. Soc. Neurosci. Abstr. 6: 529.

Grossman, S. P. (1960) Eating or drinking elicited by adrenergic stimulation of the hypothalamus. Science 132: 301-302.

Heffner, T. G., J. A. Hartman, and L. S. Seiden (1980) Feeding increases dopamine metabolism in the rat brain. Science 208: 1168-1170.

Hommel, H., U. Fischer, K. Retzlaff, and H. Knofler (1972) The mechanism of insulin secretion after oral glucose administration. II. Reflex insulin secretion in conscious dogs bearing fistulas of the digestive tract by sham-feeding of glucose or tap water. Diabetologia 8: 11-116.

Jacobowitz, D. M., T. Cooper, and N. B. Barner (1967) Histochemical and chemical studies of the localization of adrenergic and cholinergic nerves in normal and denervated cat hearts. Circ. Res. 20: 289-298.

Krebs, H. A., D. H. Williamson, M. W. Bates, M. A. Page, and R. A. Hawkins (1971) The role of ketone bodies in caloric homeostasis. Adv. Enzyme Regul. 9: 387-409.
Larner, J., and R. C. Haynes, Jr. (1975) Insulin and oral hypoglycemic drugs; glucagon. In The Pharmacological Basis of Therapeutics, I. S. Goodman and A. Gilman, eds., pp. 15071533, Macmillan Publishing Co., New York.

Leibowitz, S. F. (1975) Pattern of feeding and drinking produced by hypothalamic norepinephrine injection in the satiated rat. Physiol. Behav. 14: 731-742.

Lorden, J. F., G. A. Oltmans, and D. L. Margules (1975) Central catecholamine levels in genetically obese mice (obob and dbdb). Brain Res. 96: 390-394.

Maker, H. S., D. D. Clarke, and A. L. Lajtha (1976) Intermediary metabolism of carbohydrates and amino acids. In Basic Neurochemistry, G. J. Siegel, R. W. Albers, R. Katzman, and B. W. Agranoff, eds.,. pp. 279-307, Little, Brown and Co., Boston.

Marshall, J. F., and P. Teitelbaum (1973) A comparison of the eating in response to hypothermic and glucoprivic challenges after nigral 6-hydroxydopamine and lateral hypothalamic electrolytic lesions in rats. Brain Res. 55: 229-233.

Mayer, J. (1955) Regulation of energy intake and the body weight; the glucostatic theory and the lipostatic hypothesis. Ann. N. Y. Acad. Sci. 63: 15-43.

Maynert, E. W., and R. Levi (1964) Stress-induced release of brain norepinephrine and its inhibition by drugs. J. Pharmacol. Exp. Ther. 143: 90-95.

McCaleb, M. L., and R. O. Myers (1979) Striated dopamine release is altered by glucose and insulin during push-pull perfusion of the rat's caudate nucleus. Brain Res. Bull. 4: 651-656.

Miselis, R. R., and A. N. Epstein (1975) Feeding induced by intracerebroventricular 2-deoxy-D-glucose in the rat. Am. J. Physiol. 229: 1438-1447.

Muller, E. E., A. Pecile, D. Cocchi, and V. R. Olgiati (1974) Hyperglycemic or feeding response to glucoprivation and hypothalamic glucoreceptors. Am. J. Physiol. 226: 1100-1109.

Novin, D., D. A. Vanderweele, and M. Rezek (1973) Infusion of 2-deoxy-D-glucose into the hepatic-portal system causes eating: Evidence for peripheral glucoreceptors. Science 181:858860.

Oldendorf, W. H. (1971) Brain uptake of radiolabeled amino acids, amines and hexose after arterial injection. Am. J. Physiol. 221: 1629-1639.

Park, C. R., L. H. Johnson, J. H. Wright, Jr., and H. Batsel (1957) Effect of insulin on transport of several hexoses and pentoses into cells of muscle and brain. Am. J. Physiol. 191: $13-18$.

Ritter, R. C., and A. N. Epstein (1975) Control of meal size by central noradrenergic action. Proc. Natl. Acad. Sci. U. S. A. 72: $3740-3743$.

Ritter, R. C., and M. A. Miller (1978) Glucose fails to suppress 2-deoxyglucose-induced feeding after the onset of glucoprivation. Soc. Neurosci. Abstr. 4: 553.

Ritter, R. C., and P. G. Slusser (1980) 5-Thio-D-glucose causes increased feeding and hyperglycemia in the rat. Am. J. Physiol. 238: E141-E144.

Ritter, R. C., M. Roelke, and M. Neville (1978) Glucoprivic feeding behavior in absence of other signs of glucoprivation. Am. J. Physiol. 234: E617-E621.

Ritter, S., and R. C. Ritter (1977) Protection against stressinduced brain norepinephrine depletion after repeated 2deoxy-D-glucose administrations. Brain Res. 127: 79-184.

Ritter, S., C. D. Wise, and L. Stein (1975) Neurochemical regulation of feeding in the rat: Facilitation by $\alpha$-noradrenergic, but not dopaminergic receptor stimulants. J. Comp. Physiol. Psychol. 88: 778-784.

Ritter, S., N. L. Pelzer, and R. C. Ritter (1978) Absence of glucoprivic feeding after stress suggests impairment of noradrenergic neuron function. Brain Res. 149: 399-411. 
Ritter, S., S. I. Bellin, and N. L. Pelzer (1981) The role of gustatory and postingestive signals in the termination of delayed glucoprivic feeding and hypothalamic norepinephrine turnover. J. Neurosci. 1: 1354-1360.

Robinson, A. S., and D. H. Williamson (1980) Physiological roles of ketone bodies as substrates and signals in mammalian tissues. Physiol. Rev. 60: 143-187.

Rowland, N., and E. M. Stricker (1979) Differential effects of glucose and fructose infusions on insulin-induced feeding in rats. Physiol. Behav. 22: 387-389.

Russek, M. (1970) Demonstration of the influence of an hepatic gluco-sensitive mechanism on food intake. Physiol. Behav. 5: 1207-1209.

Russek, M. (1975) Current hypotheses in the control of feeding behavior. In Neural Integration of Physiological Mechanisms and Behavior, G. J. Mogenson and F. R. Calarescu, eds., pp. 128-147, University of Toronto Press, Toronto.

Saifer, A., and S. Gerstenfeld (1958) The photometric microdetermination of blood glucose with glucose oxidase. J. Lab. Clin. Med. 51: 448-460.

Saller, C. F., and L. A. Chiodo (1980) Glucose suppresses basal firing and haloperidol-induced increases in the firing rate of central dopaminergic neurons. Science 210: 1269-1271.

Slangen, J. L., and N. E. Miller (1969) Pharmacological tests for the function of hypothalamic norepinephrine in eating behavior. Physiol. Behav. 4: 543-552.

Slusser, P. G., and R. C. Ritter (1980) Increased feeding and hyperglycemia elicited by intracerebroventricular 5-thioglucose. Brain Res. 202: 474-478.

Smith, G. P., and A. N. Epstein (1969) Increased feeding in response to decreased glucose utilization in the rat and monkey. Am. J. Physiol. 217: 1083-1087.

Smith, G. P., and A. W. Root (1969) Effect of feeding on hormonal responses to 2-deoxy-D-glucose in conscious monkeys. Endocrinology 85: 963-966.

Smith, M. H. (1966) Effects of intravenous injections on eating. J. Comp. Physiol. Psychol. 61: 11-14.

Somogyi, M. (1951) Effect of insulin hypoglycaemia on alimentary hyperglycaemia in man. J. Biol. Chem. 193: 859-865.

Steffens, A. B. (1976) Influence of the oral cavity on insulin release in the rat. Am. J. Physiol. 230: 1411-1415.

Stone, E. A. (1973) Accumulation and metabolism of norepinephrine in rat hypothalamus after exhaustive stress. J. Neurochem. 21: 589-601.
Stricker, E. M., and M. J. Zigmond (1974) Effects on homeostasis of intra-ventricular injections of 6-hydroxydopamine in rats. J. Comp. Physiol. Psychol. 86: 973-994.

Stricker, E. M., M. I. Friedman, and M. J. Zigmond (1975) Glucoregulatory feeding by rats after intraventricular 6-hydroxydopamine or lateral hypothalamic lesions. Science 189: 895-897.

Stricker, E. M., N. Rowland, C. F. Saller, and M. I. Friedman (1977) Homeostasis during hypoglycemia: Central control of adrenal secretion and peripheral control of feeding. Science 196: 79-81.

Strubbe, J. H., and A. B. Steffens (1975) Rapid insulin release after ingestion of a meal in the unanesthetized rat. Am. J. Physiol. 229: 1019-1022.

Thierry, A. M., F. Javoy, J. Glowinski, and S. S. Kety (1968) Effects of stress on the metabolism of norepinephrine, dopamine and serotonin in the central nervous system of the rat. I. Modification of norepinephrine turnover. J. Pharmacol. Exp. Ther. 163: 163-171.

Ungerstedt, U. (1971) Adipsia and aphagia after 6-hydroxydopamine induced degeneration of the nigro-striatal dopamine system. Acta Physiol. Scand. Suppl. 367: 95-121.

Van der Gugten, J., and J. Slangen (1977) Release of endogenous catecholamines from rat hypothalamus in vivo related to feeding and other behaviors. Pharmacol. Biochem. Behav. 7: 211-219.

Van der Gugten, J., J. deKloet, D. H. G. Versteeg, and J. Slangen (1977) Regional hypothalamic catecholamine metabolism and food intake regulation in the rat. Brain Res. 135 . 325-336.

Wayner, M. J., A. Cott, J. Millner, and R. Tartaglione (1971) Loss of 2-deoxy-D-glucose induced eating in recovered lateral rats. Physiol. Behav. 7: 881-884.

Weiner, N. (1974) A critical assessment of methods for the determination of monoamine synthesis turnover rates in vivo. In Neuropharmacology of Monoamines and Their Regulatory Enzymes, E. Usdin, ed., pp. 143-159, Raven Press, New York.

Williamson, D. H., S. R. McKeown, and V. Ilic (1975) Metabolic interactions of glucose, acetoacetate and insulin in mammarygland slices of lactating rats. Biochem. J. 150: 145-152.

Yin, T. H., and C. T. Tsai (1973) Effects of glucose on feeding in relation to routes of entry in rats. J. Comp. Physiol. Psychol. 85: 258-264. 